\title{
Revisiting Contextualism in Political Theory: Putting Principles into Context
}

\author{
Tariq $\operatorname{Modood}^{1} \cdot \operatorname{Simon}_{\text {Thompson }}^{2}$
}

(C) The Author(s) 2017. This article is an open access publication

\begin{abstract}
In this article, we articulate and defend a contextual approach to political theory. According to what we shall call 'iterative contextualism', context has two important roles to play in determining what is required by justice. First, it is through the exploration and evaluation of multiple contexts that general principles are devised, revised and refined. Second, significant weight should be given to the norms to be found in specific contexts because the people affected by those norms strongly identify with them. Having said this, the application of general principles to particular contexts may still result in recommendations which deviate to some degree from the prevailing norms. In this case, we shall argue that although justice requires something other than what local norms say, what is required is likely to be intimated by the relevant context. Thus, whilst considerations of identification act as significant constraints on iterative contextualists' thinking, the idea of intimations provides them with an important resource.
\end{abstract}

Keywords Context $\cdot$ Hate speech $\cdot$ Norms $\cdot$ Oakeshott $\cdot$ Principles

\section{Introduction}

When considering what justice requires in a particular situation, political theorists may feel two impulses. One is to draw back from that situation, in order to search for universally valid and objectively grounded knowledge of justice which can be

Simon Thompson

simon.thompson@uwe.ac.uk

Tariq Modood

t.modood@bristol.ac.uk

1 School of Sociology, Politics and International Studies, University of Bristol, Bristol, UK

2 Department of Health and Social Sciences, University of the West of England, Bristol, UK 
applied to each and every situation in which relevantly similar issues of fairness are at stake. The other impulse is to get closer to the particular situation with which they are concerned, in an attempt to determine what is required of justice by immersing themselves in the specific details of this local context. Thus for every Plato seeking knowledge of an eternal and unchanging idea of justice, there is an Aristotle developing a detailed typology of existing political systems in order to understand how best to fashion constitutions for peoples with different characteristics and resources. In our own time, we may say that for every Cohen (2008) seeking to articulate principles of justice wholly independent of any facts about the world as we know it, there is a Walzer (1983) arguing that what justice requires is highly dependent on the meaning of the social goods available to be distributed in each particular political community.

In this article, we articulate and defend a way of doing political theory which is much closer in spirit to Aristotle and Walzer than to Plato and Cohen. However, given that there is a wide range of contextualist political theories, we need to show where our version is located in this range, and more importantly we need to demonstrate what is distinctive about it. One way in which we can begin to do this is by reference to Sune Lægaard's recent analysis of different forms of contextualism in contemporary political theory. For our current purposes, three of these forms are of particular importance. First, for methodological contextualism, context 'is relevant... in the formulation and critical testing and modification of the theory' (2015, p. 6). Here Lægaard is thinking of John Rawls's method of reflective equilibrium. Second, there is applicatory contextualism, according to which 'context co-determines what implications general principles have for particular cases or kinds of cases' (2015, p. 10). Third, for theoretical contextualism 'context... determines the scope, function and normative standards... of political theory' (2015, p. 13). On this version of contextualism, in other words, the interpretation of a context is a way not just of formulating principles but also of justifying them as 'appropriate for this specific context' $(2015, \mathrm{p} .16)$. What we shall call iterative contextualism shares elements with each of these three forms. First, it endorses a variant of reflective equilibrium, although we refer more often to Joseph Carens's notion of reflective disequilibrium. Second, our position also resembles that of applicatory contextualism insofar as we argue that it is the interaction of contextual facts and cross-contextual principles which generates specific conclusions about the requirements of justice. We deny, however, that it does so in the way that Lægaard describes. Third, we agree with theoretical contextualism that the interpretation of context is vital to the justification of principles. But we reject Lægaard's claim that to endorse this view is to assume that principles can simply be read off from contexts.

Having put our conception of contextualism into some context, we can now outline the distinctive features of our position. Our key claim is that context has two important roles to play in determining what is required by justice. First, it is through the exploration and evaluation of multiple contexts that general principles are devised, revised and refined. Second, significant weight should be given to the norms to be found in specific contexts because the people affected by those norms strongly identify with them. Of course, all political theorists who regard themselves 
as contextualists will agree that context has a crucial role to play in determining what justice requires. In this case, we shall need to show that our version of this claim is distinctive and at least worthy of serious consideration. One distinguishing feature of our argument will be the claim that, although what is just will depend to a significant degree on the nature of the local context, the application of general principles to particular contexts may still result in recommendations which deviate to some degree from the prevailing norms. In this case, we shall argue that, although justice requires something other than what local norms say, what is required is likely to be intimated by the relevant context. Thus, whilst considerations of identification act as significant constraints on iterative contextualists' thinking, the idea of intimations provides them with an important resource. We shall draw on Michael Oakeshott's notion of the 'pursuit of intimations' in order to explicate this part of our argument (1951).

In the next section, after sketching three contemporary contextualists' conceptions of context, we draw on these in order to outline our own conception. In the section that follows, we explain why we argue that theorists should formulate and finesse their principles by seeing how they apply in a variety of such contexts. In the section after that, we explain why our sort of contextualist may be critical of aspects of a particular context in the name of principles which, whilst arising out of the encounter with a number of contexts, are not wholly reducible to any of them. In the final section, we draw the various threads of our argument together, emphasizing the close relationship between general principles and particular contexts. We illustrate our argument throughout by reference to the problems and challenges presented by the multicultural character of contemporary states, focusing in particular on laws criminalizing the incitement of hatred against groups defined by race, ethnicity and religion. We do so partly because this is an area with which we are familiar, but also because we hope to contribute to a lively ongoing debate about methodology in political theory which focuses specifically on multiculturalism (e.g. Carens 2000, 2004; Bader and Saharso 2004; Parekh 2005; Levy 2007; Lægaard 2008, 2009, 2015; Modood 2009; Modood and Thompson 2015).

\section{Characterizing Contexts}

We begin this section by presenting three different, but by no means unrelated, accounts of context to be found in the work of three well-known contemporary exponents of a contextualist method. Bearing Lægaard's analysis in mind, we believe these to be a representative sample from the full range of contextualist political theories. We then present our own conception of context as a network of norms which is associated with particular practices and institutions.

\section{Walzer's Semantic Contextualism}

It is probably true to say that Walzer's Spheres of justice (1983) remains the bestknown contemporary example of a contextualist theory of justice. In Lægaard's terms, it may be regarded as a strong form of theoretical contextualism. By calling 
this version of contextualism 'semantic', our aim is to draw attention to the importance of meanings in his account. According to Walzer, in order to understand what distributive justice requires, it is necessary to understand the meanings of the 'social goods' which are to be distributed. The first thing to note about these goods is that there is always a multiplicity of them which may be distributed justly or unjustly (1983, p. 3). Furthermore, Walzer emphasizes that there is no single correct procedure for distributing these goods, no single agent in charge of distribution, and no single criterion by which such distribution could be ordered (1983, pp. 3-4). Social goods should, rather, be distributed by different procedures, by different agents and for different reasons (1983, p. 6). Thus Walzer asserts: 'All distributions are just or unjust relative to the social meanings of the goods at stake' (1983, pp. 8-9).

On the basis of this theory of social goods, Walzer gets to an account of a just society as one in which the distribution of each social good is autonomous: 'Every social good or set of goods constitutes, as it were, a distributive sphere within which only certain criteria and arrangements are appropriate' (1983, p. 10). If each good remains in its own sphere, so that possession of one cannot lead to possession of others, then we have a 'complex egalitarian society' (1983, p. 17). It is important to note, however, that Walzer does not regard this as an ideal society towards which all actually existing societies ought to tend. Rather, since what is just is relative to social meanings, it is possible that, where dominant social meanings take a different form, even highly inegalitarian societies — such as the Indian caste system — can be just: 'In a society where the social meanings are integrated and hierarchical, justice will come to the aid of inequality' (1983, p. 313). Later on we shall make brief reference to the way in which Walzer moved away from this strong relativist position not long after the publication of Spheres of justice.

\section{Carens's Institutional Contextualism}

Carens's political theory may be understood as a combination of what Lægaard calls methodological and applicatory contextualism. Rather than focus on the meanings of social goods, Carens conceives of context in terms of concrete practices and institutions. As he says, 'a contextual approach to political theory encourages us to begin thinking about citizenship by reflecting upon existing practices' (2000, p. 176). His reason for looking at existing practices and institutions is that 'forms of wisdom' may be 'embedded' in them (2000, p. 13; and see 2004, p. 121). He is aware of - and unembarrassed by - the genealogy of such a notion: 'The idea that established institutions and practices may contain forms of wisdom that theories fail to capture is a Burkean insight, of course, but I do not see why it should be restricted to conservatives' (2004, p. 122).

Having said this, it must be emphasized that Carens's position does not amount to a naive and uncritical endorsement of all existing institutions. He acknowledges that the characteristic danger of contextualism is that it may fail to recognize existing injustices (2000, p. 4). This, for Carens, is not a reason to abandon his approach:

In the version I am advocating, a contextual approach to theory does not entail granting normative priority to the way we do things now. It simply imposes an 
obligation to reflect upon the way we do things and what that may teach us. Practice is not given a privileged position in relation to theory. It is simply given standing. (2004, p. 122)

This is, however, a standing that must be challenged: it is necessary, as Carens puts it, for a contextual approach to move back and forth between principles and practices-following what he calls a method of 'reflective disequilibrium' (2000, p. 5; and see 2004, p. 122). We shall present our own version of this method below.

\section{Miller's Relational Contextualism}

What we are calling Miller's 'relational contextualism' is probably best regarded as a form of Lægaard's applicatory contextualism in which context and principle are co-determined. In contrast to both Walzer and Carens, Miller's focus is strongly on the relationships between the people to be found in a particular context. His basic claim is this: "If we want to understand what social justice means-justice among the citizens of a large modern society-we need to examine the many different ways in which they associate with each other' (2013, pp. 5-6; and see p. 7). Relationships are of fundamental importance since they explain who owes what to whom and why. Furthermore, since there are different kinds of relationship, the specific kind operating in a particular situation must be identified in order to understand what justice requires there. As Miller says, on his version of contextualism, context is defined 'by reference to the kind of social relationship that exists among the parties between whom justice is to be done; the principle that should be used to determine whether an allocation of resources in each of these contexts is just will depend on which kind of relationship obtains' (2013, p. 48).

Miller's fundamental idea, that context is to be characterized in terms of relationships from which the requirements of justice can be inferred, is worked out in detail in his Principles of social justice. There he identifies three 'basic modes' of human relationship which he calls 'solidaristic community, instrumental association, and citizenship' (1999, pp. 25-26). In each of these types of relationship, a distinctive principle of justice should prevail: a criterion of need applies in the case of solidaristic community, one of desert in instrumental associations and one of equality in the case of citizenship (1999, pp. 26-30). Having said this, it is important to understand that, for Miller, an account of justice which is sensitive to context is not one that simply endorses the conventions which prevail in any particular situation. Rather, he argues that justice is achieved when the conventions governing a context are appropriate to it. The crucial implication is that, when those conventions are not appropriate, they may be legitimately criticized (2013, pp. 49-50).

\section{Normative Practices}

In order to introduce our own conception of context, a couple of observations about the three conceptions that we have just sketched are in order. The first is that, at least for the purposes of our current argument, these conceptions may be regarded as offering different perspectives on the same object. In order to see this point, 
consider how deeply interrelated goods, institutions and relationships are; it is difficult, we would suggest, to imagine a situation in which one is present without the others being there too. For example, institutions and relationships are linked since most sorts of relationship are only possible if certain institutions exist. Miller makes this point himself, acknowledging that what we are calling his relational account 'ignores the fact that people who are related in one or more of these three basic ways will usually also have an institutional relationship, defined by the law or by other rules and procedures' (1999, p. 26). In a similar way, all of the social goods on which Walzer focuses are exchanged in relationships and/or distributed through institutions. Membership, for instance, takes the form of relationships between citizens, and depends for its existence on the institutions of the state (Walzer 1983, chapter 2).

Building on this observation that the three forms of contextualism on which we have focused describe the same sort of object from three different perspectives, we want to offer a conception of contexts which describes the object underlying all of these accounts. Hence we propose to characterize contexts as normative practices, a phrase we use as shorthand for networks of norms strongly associated with particular sets of practices. By use of the word normative, we intend to focus on the norms which we understand as elements of the moral grammar of each particular context. For our purposes, norms may be regarded as rules that shape and direct behaviour, enabling the actions of a number of individuals to be coordinated in pursuit of a common purpose or activity of some kind. ${ }^{1}$ But it must be understood that we use this word norm to encompass a wide range of evaluative and actionguiding entities, including, for example, values, ideals, rules, maxims, tenets, morals and goods. Returning to Walzer, Carens and Miller, then, we can say that there are norms present in goods, institutions and relationships which prescribe how these objects should be distributed, organized or conducted. Norms, in other words, shape our understanding of social goods, mould and flow through institutions, and facilitate and govern our relationships with one another.

Following on from this last remark, the second observation we want to make is that the three contextualist theories which we have discussed may at some points give a misleading impression of the relationship between particular contexts and general principles. On Miller's account, for instance, it might appear that it is possible to get from an entirely factual account of the type of relationship present in a particular context to a normative conclusion about the sort of principle of justice which should prevail in that context. The reason why this is misleading is that sets of relationships are always already suffused with and regulated by norms, which are vital to maintain the character and the continuing existence of these relationships. In a relationship of solidaristic community, for example, individuals are attentive to one another's needs; if they were not, then that relationship would not exist (or at least it would not be a relationship of that kind). The same reasoning applies, ceteris paribus, to Walzer's social goods and Carens's institutions. In Walzer's terms, part of the meaning of a good is an account of how it should be distributed. It is arguable

\footnotetext{
${ }^{1}$ Compare Aaron James's definition of a social practice (2013, p. 44$)$.
} 
that, in Carens's case, part of the 'wisdom' that an institution may contain is to be found in the norms which regulate it.

This second observation that norms are always intimately connected to goods, institutions and relationships explains why we characterize a context as a normative practice, where we use this word to refer to any more or less organized pattern of human behaviour. For us, then, rather than being elements of free-floating networks of ideas, norms are strongly associated with and rooted in particular goods, institutions and relationships, and have concrete institutional locations, including parliaments, courts, schools, political parties, social movement organizations, businesses and so on. We would suggest that by connecting norms to practices in this way we can avoid the error of assuming that it is possible to infer principles of justice directly from value-free accounts of contexts. Since such contexts are necessarily normative in character, they are not logically different in kind from the principles which we believe should regulate them. As we shall see below, the fact the norms are always entwined with practices also has significant implications regarding the feasibility of normative principles.

Before considering how the iterative contextualist formulates her principles by reference to contexts understood in the way just described, a couple of final remarks are in order. First, the norms which animate practices range in character from highly complex and fully articulated principles, such as widely promulgated constitutional principles and statutory laws, to largely unspoken and informal rules of behaviour, such as rules of civility, which may be broadly understood and followed even though they are rarely if ever articulated. In this article, we focus on a number of formal norms to be found in legal systems. But nothing would stop our method also being applied to more informal codes such as that of civility, or to issues of social justice such as fair taxation. Second, the practices containing such norms may range considerably in size and scale, including the legal, political or educational system of a particular state, and the culture of a specific group of people or of a particular organization within that state. As we shall see in the next section, normative practices also exist at regional and global levels above individual states. For instance, the European Convention on Human Rights contains a set of legal norms with authority over the 47 member states of the Council of Europe, and the Universal Declaration of Human Rights seeks to provide a common standard of human rights for 'all peoples and all nations'. Third, as we shall see in the section after next, norms always require interpretation, and they may always be interpreted in different ways. Furthermore, more than one norm may be found in any particular practice, and these may come into conflict with each other, making it inevitable that choices must be made between them.

\section{Formulating Principles}

We now shift our attention to the way in which an iterative contextualist formulates the principle or set of principles of justice which she regards as appropriate to evaluate the sort of contexts that we have just described. We shall show how this theorist initially generates her principles, and how she then refines and revises them 
as she sees how they apply across a number of different contexts. In order to do this, we shall focus on one particular political issue, namely that of hate speech, and consider how the iterative contextualist might develop principles capable of determining the appropriate way to deal with expressions of this kind.

Before we begin, a word of caution is needed. Our account will be somewhat abstract, in one specific sense. At various points, we suggest that our theorist may decide to modify her principle in some way, so that it incorporates a new norm or encompasses a different range of groups. But we do not explain in detail why she might decide to do so. We shall, in other words, abstract from the first-order argument about what hate speech regulation should be like in order to focus on the second-order argument about methodology. Such abstraction is justified, we believe, because it enables us to focus on the part of this process which is of particular concern to us, namely the relationship between the theorist's general principles and the norms to be found in the particular contexts in which she wishes to apply those principles.

\section{Generating Principles}

With that caution in mind, let us consider how the iterative contextualist initially formulates her principle or principles of justice. She begins by examining one specific context which is characterized in part by a particular set of norms. As a result of this examination, she formulates a principle which she regards as appropriate for the evaluation of that context. She then uses this principle to make a judgement about what justice requires there. This way of putting it might appear to suggest that, since she has no other normative resources on which to draw, this theorist will inevitably come up with a principle which bears a very close resemblance to the norms characterizing the context with which she is concerned. In practice, of course, political theorists will always already have a fund of normative principles at their disposal, one or more of which they may regard as relevant to the evaluation of a particular context.

Let us illustrate this account of how the contextualist first generates her principles by reference to the example of hate speech. The first context that she encounters is that part of the legal system in England and Wales which is concerned with hate speech in the period between 2001 and 2006. The theorist's aim is to decide whether the scope of the existing legislation should be extended in order to cover not only racial hatred but also hatred on the grounds of religious belief. In order to be able to do this, she must first determine which norm or norms are most relevant to decide the issue, and this in turn requires her to determine which of them makes best sense of this legislation and shows it to be of greatest value. ${ }^{2}$ Looking at existing laws on hate speech, and other cognate pieces of legislation, the contextualist determines that it is a norm of equality, where this is understood to require equal protection of an appropriate kind, which best fits the bill. ${ }^{3}$ In light of this interpretation, the

\footnotetext{
${ }^{2}$ We shall say more about the need always to interpret and sometimes to choose between norms when discussing the idea of the pursuit of intimations later on.

3 In support of this interpretation, see, for example, David Nash's and Chara Bakalis's analysis of the Racial and Religious Hatred Act (2007).
} 
theorist decides that the principle appropriate to determine whether the existing legislation should be extended is also one founded on the value of equality. Finally, by applying this egalitarian principle, she concludes that the scope of hate speech legislation should indeed be broadened so that it includes groups defined by their religious beliefs or their lack of such beliefs, since they need the same sort of protection as that enjoyed by the groups already identified by the existing laws.

\section{Refining Principles}

On our account thus far, the political theorist has examined just one particular context. The point of calling our sort of contextualism iterative, however, is to emphasize that the theorist's principles are generated, refined and revised in the process of applying them across a range of different contexts, in the encounter with a number of different sets of norms. Consider, then, how this sort of contextualist applies her principle to a new context with its own set of norms. In this process, she may conclude that her existing principle may be applied in an unchanged form to both since it is as relevant and valid in the second context as it was in the first. It seems rather more likely, however, that the examination of this new context will give her reason to refine her principle to at least some degree. In this case, it is this modified principle which she will then use to decide what justice requires in this new context. ${ }^{4}$

We can illustrate this part of the process by staying with the same example of hate speech, but now considering a second context. Let us focus once more on the legal system of a particular state. In France, the key legislation in this area is the Law of the Freedom of the Press of 1881, amended on several occasions since it was first promulgated, but still in force today. Again the theorist's task is to determine which sorts of group should be protected by this legislation, and again, in order to be able to do this, she first needs to decide which norm or norms play the most important part in the justification of this legislation. In this context, she makes particular note of Articles 32 and 33 of the 1881 Law which criminalize defamatory communication about a range of groups. Having thus examined the French Law and its various amendments, our contextualist concludes that protection against defamation-the harm to a person's reputation which may be caused by the expression of falsehoods about them-is one of the most important norms animating the French legislation.

Understanding the importance of this norm in the context of the French legal system may then give the contextualist reason to refine her original principle. Having considered this new context, the theorist now believes that the idea of reputational damage provides an important insight into the nature of the harm which

\footnotetext{
${ }^{4}$ Clearly there is more to be said about the details of the process by which the iterative contextualist compares her existing principles to the norms to be found in each new context she considers. In the field of political theory, for instance, there is a growing literature on the comparison of political concepts (e.g. Freeden and Vincent 2012). In a similar vein, legal and constitutional scholars have been refining accounts of how to systematically compare constitutions (e.g. Ginsburg and Dixon 2011; Hirschl 2014). Both of these approaches contain resources on which we would wish to draw if we had the space for a complete exposition of this part of our position.
} 
hate speech may do, against which equal protection needs to be provided. ${ }^{5}$ Thus she fleshes out her original principle by incorporating this insight into it. Having done so, applying her revised principle leads her to conclude that it should also offer protection to groups defined by their sexual orientation ${ }^{6}$ (and, if the theorist returned to the first context, she may now believe that hate speech legislation in England and Wales should also be extended in this way). This process of refinement may be repeated on further occasions. On each occasion, the examination of a new context may give the theorist reason to finesse her principle yet further, adding new details to it in light of the insights newly gained.

\section{Revising Principles}

In describing the process by which the theorist refines her principle, we have assumed up to this point that its essence remains the same, but that a series of further nuances are added to it, just as — to be a little fanciful — an oyster adds further layers of nacre to a pearl. However, as she examines a new context, the contextualist may have good reason not just to fine-tune her principle in some way but also to revise it to some significant degree, perhaps by removing some of its particular components and replacing them with others. Furthermore, as a result of such a revision to her principle, the theorist's evaluation of a particular context may also change, which may then give her reason to revise her principle once more. Nor is this necessarily a once-and-for-all change, since the theorist's new evaluation of a context may then give her reason to modify her principle yet again.

Here we see in effect a version of a process of reflective equilibrium much like that Rawls describes in his Theory of justice (1971), although for us the process we have described has one significant difference. For Rawls, reflective equilibrium is an oscillating movement between a theorist's particular moral judgements and her general principles. ${ }^{7}$ For us, by contrast, this back-and-forth movement is between our evaluation of a set of norms to be found in a particular context and the principles which we believe apply to that context. On our account, in other words, one half of the circular process of reflective equilibrium describes the way in which general principles may be revised as a result of the encounter with plural sets of norms, whilst the other half of the circle describes the process by which the modified principles are then used to pass revised judgement on those sets of norms. In theory, this process of mutual adjustment may continue without end, as further rounds of revised evaluations and revised principles are possible, in a variation of the process which, as we have seen, Carens calls reflective disequilibrium.

In order to introduce this part of our account, we shall return once more to the example of hate speech regulation. It may be recalled that at the end of the previous section we said that relevant contexts may exist at various levels, including the

\footnotetext{
5 On the idea that a notion of 'group defamation' may provide an important justification for hate speech regulation, see Waldron (2012).

6 See McCaffrey (2005, pp. 208-209).

7 This is what Rawls later calls narrow - in contrast to wide - reflective equilibrium; see Daniels (2011) on the difference between the two.
} 
local, national, regional and even global. In the case of hate speech, one clearly relevant context is the legal regime shaped by the European Convention of Human Rights and presided over by the European Court of Human Rights. Thus, having looked at the laws of two particular states, our contextualist now turns her attention to the European context in which hate speech legislation is formulated and enforced. She observes that one of the ways in which the Court seeks to determine whether a particular expressive act should be regulated is to consider whether it constitutes an abuse of the right to freedom of expression because it negates the Convention's fundamental values. For example, in the case of Pavel Ivanov v. Russia (2007), the Court decided that the applicant's anti-Semitic newspaper articles were not protected speech since such 'a general and vehement attack on one ethnic group is in contradiction with the Convention's underlying values, notably tolerance, social peace and non-discrimination' (European Court Of Human Rights 2007). Let us say that, as a result of her examination of this new context, our contextualist decides to revise her principle, believing that another legitimate objective of hate speech legislation is to protect these values. Let us also say that, after reflecting on this new context, the theorist also comes to the view that it makes no sense to say that groups can be defamed, and thus she abandons that particular element of her principle. Both of these changes may also give her reason to change the scope of her principle, including groups previously left out, or excluding groups previously protected.

In drawing this part of our argument to a close, let us emphasize one point in particular. According to what we are calling iterative contextualism, the theorist generates, refines and revises her principles through the examination of a series of particular contexts. As a result of this process, she may legitimately conclude that a principle is applicable to all of these contexts. This does not imply, however, that at some point this principle can float free of all particular contexts, and thenceforth apply with equal validity to any context at all. On our position, rather, the theorist can only say with confidence that a cross-contextual principle is applicable across that specific range of contexts which she has examined and in which she has concluded that it is germane. This does not mean that all principles must necessarily have a narrow range of application. Perhaps a hate speech regulation which explicitly prohibits racist chanting at football matches is necessary in Scotland, but nowhere else. Perhaps a regulation which prohibits Holocaust denial is required in a number of European states, including Austria, Germany and Romania, but not in all. Perhaps one part of the rationale for hate speech regulation, such as an idea of human dignity, will turn out to apply to all actual contexts. To underline our main point, however, this is not because it is valid independent of any context, but rather because it turns out that it is relevant to all.

\section{Applying Principles}

Thus far we have explained why the iterative contextualist regards contexts as networks of normative practices, and how she formulates her principles by considering how they pertain to a number of such contexts. Now we need to show in more detail how she applies these principles in a particular context. We shall begin 
by showing that, on our position, what is suggested by a principle of justice will very often deviate to at least some degree from existing norms. Then we shall explain why we nevertheless do not give absolute priority to the demands of justice since we give significant weight to those norms. Finally, if and when the dictates of local norms and the demands of justice come apart, we show how it may be possible to balance these two sets of considerations in a coherent and principled way.

\section{Criticizing Norms}

One frequently voiced criticism of contextualist political theories is that they can do no more than endorse existing political arrangements, no matter how just or unjust these may be (according to some external standard of justice). Against this view, all three of the contextualists we considered above explain why, on their accounts, it is possible to criticize such arrangements. Walzer's account of internal and external criticism (1987), Carens's idea of reflective disequilibrium (2004, p. 122) and Miller's distinction between contextualism and conventionalism (2013, pp. 49-50) all provide justifications for taking a critical perspective on existing sets of norms. Like these three, our sort of contextualist also seeks to achieve critical distance from the norms which characterize the contexts with which she is concerned. We now want to explain how it is possible for her principle of justice to provide a standard by which local norms can be criticized.

The best way to do this is to return to the case of hate speech. In our account of how the contextualist generates her principles of justice, we saw how she considers a series of contexts, and how, in each place, she discovers distinctive justifications for hate speech laws, and distinctive accounts of the range of groups which should be protected by them. As the theorist moves from one context to the next, her principles are refined and revised in the ways we have described. Sometimes further reasons are incorporated into her account of the rationale for legislation against hate speech, whilst at other times reasons which she had included are now abandoned. As we suggested earlier on, the contextualist may ditch the idea of group defamation, but add the idea that hate speech regulation protects social peace. At the same time, her account of the appropriate scope of such laws changes, as she sometimes adds a new group, but occasionally drops another. For the sake of argument, let us say that she adds members of the travelling community, ${ }^{8}$ but for some reason now excludes those defined by their lack of religious belief.

Given the nature of this iterative process, it should be clear why, on our account, what justice requires in each particular context is never a simple and direct function of the norms to be found there. Although principles are generated by a process of reflection on context, because this process is iterated across a number of such contexts, the principle which emerges will be at variance with the set of norms which characterize any one of them. For instance, whilst it applies to the French legal system, it does not accept the idea that hate speech laws are justified because they protect groups against defamation. It also applies to England and Wales, but does not endorse that jurisdiction's assumption that the scope of hate speech laws

\footnotetext{
${ }^{8}$ See, for example, Ireland's Prohibition of Incitement to Hatred Act 1989.
} 
should extend to those who lack religious beliefs. In this way, the iterative contextualist's general principle provides a standard of judgement which is to some degree critical of the normative practices to be found in any one of the contexts from which it was forged.

\section{Valuing Norms}

However, it does not follow from what we have just said that, whenever the iterative contextualist's principle of justice is out of line with existing norms, the former takes absolute priority over the latter, so that the people in that context are obliged to bring their normative practices into line with the demands of justice. This is because she believes that there are a number of important considerations which must be borne in mind when seeking to reach an all-things-considered judgement about what should be done in each particular situation. To be more specific, she accepts that there are several sorts of constraint-practical, behavioural and normativewhich she must place on her reasoning in order to apply her principle of justice in such a way that it is tailored (to some degree) to the character of each context. ${ }^{9}$

First, then, there are practical constraints which concern the feasibility of different courses of action. The practices, structures and institutions which characterize a particular context at a particular time render a number of options entirely unfeasible, and make some options much less feasible and much more difficult to implement than others. Such limits and constraints need to be taken into account if the theorist is to avoid insisting on changes to existing normative practices which have no chance whatsoever of being implemented. Having said this, it seems reasonable to hope that this will be less of a problem for iterative contextualism than for some other approaches to political theory. The fact that this theorist's principles emerge from her exploration of a number of specific contexts means that there is unlikely to be too large a gap between her principles and norms to be found in those contexts. To put it more positively, there is a good chance that this theorist's conclusions about what should be done in a particular situation will be feasible, in Gilabert's and Lawford-Smith's sense of 'a state of affairs' which 'one we could actually bring about' (2012, p. 809). There is much more that can and should be said about the significance of the hitherto relatively neglected issue of feasibility, but for reasons of space we cannot do so here. ${ }^{10}$

Second, when applying her general principle in a particular situation, the iterative contextualist is also cognizant of certain behavioural constraints which concern how we can reasonably expect people to behave, and in particular about the extent to which we may reasonably expect them to change the way they behave. In the spirit of the practical sort of constraint just mentioned, it is no good insisting that justice requires conformity to some particular pattern of behaviour if there is no chance of the people concerned actually behaving in that way. But it is important to emphasize

\footnotetext{
${ }^{9}$ Our account of these three constraints resembles to some extent a number of the constraints and prerequisites which Carens identifies as elements of what he calls a 'realistic' approach to morality (1996).

${ }^{10}$ Gilabert and Lawford-Smith (2012) provide an excellent introduction to this concept.
} 
that we do not see people's likely behaviour simply as an obstacle which can get in the way of the achievement of justice. On our account, rather, independent normative weight is given to the fact that people's sense of who they are, what larger community they are part of, and what they believe and value, are all shaped in part by the norms embodied in the practices, structures and institutions which form the context of their lives. Given such identification, changes to existing norms, and thus to the institutions and practices with which they are associated, come at a price to the individuals affected by them. Such changes are likely to have profoundly disruptive effects on them, since they are forced to detach themselves from norms which had hitherto given them a significant part of their sense of identity. For us, it follows that, when seeking to determine what the requirements of justice in a particular situation are, the contextualist must pay attention to the identity-related costs which would have to be borne by those individuals whose lives would be affected by any changes which the implementation of those requirements would involve. This should not be the contextualist's sole consideration, and certainly not one that should outweigh all others, but it is one to which she should give significant weight.

The third and final sort of constraint which the iterative contextualist imposes on her thinking about justice is normative in character. To accept such a constraint is to give particular consideration to the ideals and values that the people in a particular context presently endorse. These norms are not a practical obstacle to a theorist's desired ideal-like a limited housing stock—but are ideals in their own right, and the theorist could only achieve her independent goal if people did not value what they in fact do value, if they thought differently. To see why this sort of constraint should be adopted, consider Aaron James's defence of what he calls 'the practicebased method of justification' of principles of social justice (2013, p. 43). He suggests that political theory is an activity which may have a variety of legitimate purposes, and that the purpose chosen will determine the manner in which it is pursued. For example, 'our theoretical aims' may be 'purely intellectual in the following sense: we seek to justify requirements of justice for a stipulated set of social circumstances that are, for some good reason, of interest to us' (2013, p. 48). In this case, the way in which we think about justice will not necessarily-but may-be entirely insensitive to current practices. If, however, 'our aim is... to justify principles as normative for us', then 'we have a natural rationale for beginning from the social practices we already have... our argument then has a firm normative footing, a footing from which to mount moral arguments about what the demands of justice are' (2013, p. 56). Following James's analysis, we understand iterative contextualism to be a political theory of the second kind. We aim, in our case, to understand what justice requires people to do in particular contexts, and therefore the character of the norms which characterize each context will play an important role in our thinking, not just as facts but as constituting the normative context. 


\section{Pursuing Intimations}

Thus far we have argued that the iterative contextualist can criticize existing normative practices in the name of her cross-contextual principles, whilst at the same time we have suggested that there are good reasons why she should give special weight to those existing practices in her reasoning. Thus this theorist determines what justice requires in a particular situation by applying her principles to it in a way which is responsive to its specific circumstances. There is, no doubt, a certain tension between these two aspects of our account: valuing existing norms, on the one hand, and criticizing them in the name of principles, on the other. Although this tension cannot - and should not—be resolved, we nevertheless want to end this section by suggesting that, in at least some situations, it may be possible to ease it to some degree.

Our inspiration here is Oakeshott's account of the practice which he calls 'the pursuit of intimations'. We believe that three aspects of his account can be incorporated into our iterative contextualism. First, Oakeshott contends that political activity necessarily takes place within 'recognized traditions of behaviour' (1962, p. 123). Such traditions are, at least for the purposes of the current argument, sufficiently similar to our conception of contexts as complex networks of normative practices. Second, these traditions have several important characteristics: they are 'neither fixed nor finished', they have 'no changeless centre', and no part of them is 'immune from change' (1962, p. 128). Third, given these first two aspects of Oakeshott's account, he regards politics as the activity of pursuing and making choices between the intimations or sympathies that we find in these traditions: 'political reasoning', he suggests, involves 'the convincing exposure of a sympathy, present but not yet followed up, and the convincing demonstration that now is the appropriate moment for recognizing it' (1962, p. 124).

Oakeshott's idea of 'the pursuit of intimations' suggests that we need to add further complexities to our account of the way in which the iterative contextualist assesses each of the particular contexts with which she is concerned. Thus far we have assumed that there is only one norm germane to each particular context, and that this norm can only bear one interpretation. In practice, however, matters are rarely as straightforward as this: there will generally be more than one norm present in each context, and each of them may be interpreted in different ways. It follows that when the theorist examines a particular context she will face two interrelated tasks: first, to determine which norm is of most importance to it, and, second, to decide how that particular norm should be interpreted. To carry out these tasks, she will need a theory of interpretation. Here, we would suggest, the two criteria at the heart of Ronald Dworkin's interpretive method provide the right guidance. According to the first criterion, the norm selected must be one element of a plausible account of the context in question. Second, as Dworkin says, of those interpretations which fit the context, the theorist must select the one "which is "substantively" better, that is, which better promotes the political ideals he thinks 
correct' $\left(1982\right.$, p. 171). ${ }^{11}$ Our suggestion is that these further complexities present the iterative contextualist with an opportunity: namely, to offer an account of what justice requires in a particular situation which narrows-even if it does not entirely close-the gap between the existing norms and her principle of justice. To put this in Oakeshott's terms, the contextualist can pursue those intimations which tend in the direction of the principle which she has developed through her consideration of contexts elsewhere.

In order to explain how this might work in practice, we shall return for a final time to our ongoing example. It may be recalled that in the case of hate speech laws in England and Wales, our contextualist determined that the key norm is that of equality. In fact, it is arguable that norms of public order and anti-discrimination are also present in this body of law (Twomey 1994). Furthermore, the norm of equality itself could be understood in terms say of equal dignity or status rather than equal protection. Why, then, pick out the norm of equality? And why interpret it in terms of equal protection? We have suggested, following Dworkin, that the right interpretation is the one which fits the existing practice and also shows it to be of greater value than other interpretations would. In this particular case, we would suggest that it is a reading of these hate speech laws in terms of the norm of equal protection which best fits this bill: there is good reason to think that this norm is an important part of the rationale for these laws, and understanding them in its terms shows them in the best light. Our claim, then, is that this method of interpretation can help to ease the tension between valuing and criticizing norms which we described at the start of this section, by enabling the iterative contextualist to give a reading of the context with which she is concerned in a way that best harmonizes with her existing principle of justice.

\section{Conclusion}

In this article, we have introduced and outlined the principal features of what we are calling an iterative conception of contextualism. In order to make the distinctiveness of our conception clear, we have focused our attention on two of its most important features. The first of these is its account of how principles in political theory are generated, refined and revised by considering the sets of normative practices to be found in a number of different contexts. Each context gives a principle a distinctive inflection, and a number of these inflections together constitute the particular character of that principle. In making this claim, our aim has been to avoid what we regard as a false choice, according to which normative principles are either formulated without regard to any context, or are regarded as direct reflections of each particular context. By suggesting that principles are developed and refined through the encounter with multiple contexts, this choice may be evaded.

The second feature of iterative contextualism on which we have focused is its account of how principles are to be applied in each particular situation. Here we

\footnotetext{
11 Compare the second and third stages of James's process of justification, which he refers to as 'characterization' and 'substantive argument' respectively (2013, pp. 45, 55-58).
} 
began by insisting that what is required by justice may not be exactly what a particular set of norms says. But we also suggested that, when seeking to determine what is required, the contextualist must bear a number of considerations in mind. To be specific, we argued that she will place certain practical, behavioural and normative constraints on her process of reasoning, thus taking into account matters of feasibility, reasonable expectations about how people may behave and the moral significance of existing norms. We ended with the suggestion that the tension between valuing existing norms but also criticizing them in the name of a principle of justice can be eased by showing how it is possible to follow the intimations to be found in a particular context in the direction of the theorist's general principles. For us, this account of the practice of political theory shows how it may be possible to avoid a second false choice, this time between giving absolute priority either to extant local norms or to context-independent general principles in deciding what is required by justice.

With these two features in mind, we can see clearly how iterative contextualism shares elements with several of Lægaard's types of contextualism, but understands and combines them in a very distinctive way. Like methodological contextualism, it endorses a form of reflective equilibrium, but in this case the equilibrium it seeks is one between contextual norms and cross-contextual principles. Similar to applicatory contextualism, it suggests that contexts and principles co-determine the requirements of justice. On our account, however, pre-existing principles are not simply refracted through particular contexts, since these principles only emerge out of the exploration of multiple contexts. Iterative contextualism also bears some resemblance to what Lægaard calls theoretical contextualism, since it supports the view that principles of justice are formulated and justified by a process of contextual interpretation. But this does not commit us to the view that such principles are no more than the reflection of contexts; rather, since principles emerge from a number of contexts, they can be critical of the norms prevailing in any one of them.

Of course, we cannot pretend to have presented a fully adequate defence of our version of contextualism here. Amongst other things, such a defence would need to offer a detailed account of the ways in which it is better than other versions of contextualism, some of which we mentioned earlier on. And it would need to build on the example provided in this article in order to show in much more depth how this form of political theory would work in practice. Amongst other things, this would include giving a more detailed account of the way in which contexts are interpreted, and how different contexts are compared to one another. This having been said, we would contend that presenting the principal features of iterative contextualism all in one go has been a worthwhile exercise. We think that this is a distinctive and coherent account of how political theory should be practised, one which is at the very least worthy of serious consideration. As we have illustrated by using the example of hate speech regulation, we believe that it is a method which may be fruitfully pursued by those engaging in the political theory of multiculturalism, but we are convinced that it is of more general applicability than that. 
Acknowledgements We would like to thank Veit Bader, Joseph Carens, Jan Dobbernack, Sune Lægaard, Bhikhu Parekh, Varun Uberoi, Albert Weale and two anonymous referees for this journal for their comments on one or more of several earlier versions of this article.

Open Access This article is distributed under the terms of the Creative Commons Attribution 4.0 International License (http://creativecommons.org/licenses/by/4.0/), which permits unrestricted use, distribution, and reproduction in any medium, provided you give appropriate credit to the original author(s) and the source, provide a link to the Creative Commons license, and indicate if changes were made.

\section{References}

Bader, Veit, and Sawitri Saharso. 2004. Introduction: Contextualized morality and ethno-religious identity. Ethical Theory and Moral Practice 7: 107-115.

Carens, Joseph. 1996. Realistic and idealistic approaches to the ethics of migration. International Migration Review 30: 156-170.

Carens, Joseph. 2000. Culture, citizenship, and community. Oxford: Oxford University Press.

Carens, Joseph. 2004. A contextual approach to political theory. Ethical Theory and Moral Practice 7 : $117-132$.

Cohen, G. A. 2008. Rescuing justice and equality. Harvard, MA: Harvard University Press.

Daniels, Norman. 2011. Reflective equilibrium. The Stanford encyclopedia of philosophy. http://plato. stanford.edu/archives/win2013/entries/reflective-equilibrium/. Accessed 6 October 2015.

Dworkin, Ronald. 1982. 'Natural' law revisited. University of Florida Law Review 34: 165-188.

European Court of Human Rights. 2007. Pavel Ivanov against Russia. 20 February 2007. http://hudoc. echr.coe.int/eng?i=001-79619. Accessed 30 September 2016.

Freeden, Michael, and Andrew Vincent. 2012. Comparative political thought: Theorizing practices. London: Routledge.

Gilabert, Pablo, and Holly Lawford-Smith. 2012. Political feasibility: A conceptual exploration. Political Studies 60: 809-825.

Ginsburg, Tom, and Rosalind Dixon. 2011. Comparative constitutional law. Cheltenham: Edward Elgar.

Hirschl, Ran. 2014. Comparative matters: The renaissance of comparative constitutional law. Oxford: Oxford University Press.

James, Aaron. 2013. Why practices? Raisons Politiques 51: 43-62.

Lægaard, Sune. 2008. Moderate secularism and multicultural equality. Politics 28: 160-168.

Lægaard, Sune. 2009. Moderate secularism, difference sensitivity and contextualism: A rejoinder to Modood. Politics 29: 77-81.

Lægaard, Sune. 2015. Multiculturalism and contextualism: How is context relevant for political theory? European Journal of Political Theory 14: 259-276.

Levy, Jacob. 2007. Contextualism, constitutionalism, and modus vivendi approaches. In Multiculturalism and political theory, ed. Anthony Laden, and David Owen, 173-197. Cambridge: Cambridge University Press.

McCaffrey, Enda. 2005. The gay republic: Sexuality, citizenship and subversion in France. Farnham: Ashgate.

Miller, David. 1999. Principles of social justice. Harvard, MA: Harvard University Press.

Miller, David. 2013. Justice for earthlings. Cambridge: Cambridge University Press.

Modood, Tariq. 2009. Moderate secularism and multiculturalism. Politics 29: 71-76.

Modood, Tariq and Simon Thompson. 2015. Defending strong contextualism. Academia.edu. https:// www.academia.edu/12725399/Defending_Strong_Contextualism.

Nash, David, and Chara Bakalis. 2007. Incitement to religious hatred and the 'symbolic': How will the Racial and Religious Hatred Act 2006 work? Liverpool Law Review 28: 349-375.

Oakeshott, Michael. 1962. Rationalism in politics and other essays. London: Methuen.

Parekh, Bhikhu. 2005. Rethinking multiculturalism, 2nd edn. London: Palgrave Macmillan.

Rawls, John. 1971. A theory of justice. Harvard, MA: Harvard University Press. 
Twomey, Anne. 1994. Laws against incitement to racial hatred in the United Kingdom. Australian Journal of Human Rights 1: 235-247.

Waldron, Jeremy. 2012. The harm in hate speech. Harvard, MA: Harvard University Press.

Walzer, Michael. 1983. Spheres of justice. New York, NY: Basic Books.

Walzer, Michael. 1987. Interpretation and social criticism. Harvard, MA: Harvard University Press. 